\title{
HABITAT FRAGMENTATION AND DEMOGRAPHIC CHANGE FOR A COMMON PLANT: TRILLIUM IN OLD-GROWTH FOREST
}

\author{
ERIK S. JULES \\ Department of Biology, University of Michigan, Ann Arbor, Michigan 48109-1048 USA
}

\begin{abstract}
I studied the influence of forest fragmentation on an understory herb, Trillium ovatum, in the Siskiyou Mountains of Oregon, where logging practices over the past $35 \mathrm{yr}$ have created a mosaic of fragments surrounded by clearcuts and tree plantations. The age of trillium plants can be estimated by counting the annual constrictions on their rhizomes. Based on data collected by Whittaker in 1949 (i.e., pre-fragmentation) and a survey I conducted in 1995, I estimated that the process of clearcutting and subsequent conifer planting results in the mortality of almost all trillium $(\sim 97.6 \%)$. In general, the remaining plants are not recruiting new individuals, even in sites clearcut $30 \mathrm{yr}$ ago. Thus, trillium is restricted to smaller amounts of remnant, uncut forest. My study also demonstrated that populations in forest remnants that were within $\sim 65 \mathrm{~m}$ of forest-clearcut edges have had almost no recruitment of young plants since the time of the adjacent clearcutting, while forest interior populations contained higher recruitment levels. Projections based on these recruitment estimates indicated that edge populations will decline in size and interior populations will not decline. This study provides the first evidence of demographic changes in plant populations resulting from habitat fragmentation, and it offers evidence for the mechanisms responsible for such demographic changes.
\end{abstract}

Key words: clearcutting; edge effects; extinction; habitat fragmentation; island biogeography; plant demography; plant diversity; Siskiyou Mountains; Trillium ovatum.

\section{INTRODUCTION}

The destruction and fragmentation of habitat results in the conversion of relatively continuous ecosystems, such as forests, into archipelagos of natural habitat surrounded by a "sea" of agriculture and urban development. In the past three decades an extensive amount of work has concerned habitat fragmentation, using both the theory of island biogeography (MacArthur and Wilson 1967) and a now well-developed literature in theoretical population biology (e.g., Shaffer 1981, Soulé 1987, Lande 1988, Ewens 1990, Lawton 1995). In general, this work suggests that populations in fragmented ecosystems are more likely to become extinct due to effects associated with smaller sizes of remnant habitat, greater isolation from neighboring populations, and increased amounts of "edge" habitat, and this should consequently lead to an overall reduction in biological diversity in the region (reviewed in Simberloff 1988, Harrison and Fahrig 1995).

Most tests of the prediction of higher population extinction rates in fragmented landscapes have been done on animals (e.g., Rolstad 1991, Verboom et al. 1991, Margules et al. 1994, Mills 1995). For plants, the effects of fragmentation have been assessed indirectly by testing for a decline in diversity with decreasing fragment size and/or isolation (e.g., Weaver and Kellerman 1981, Carelton and Taylor 1983, Gibson et al. 1988,

Manuscript received 3 May 1996; revised 22 July 1997; accepted 30 July 1997.
Dzwonko and Loster 1989). The results of these plant studies are often unclear due to some general problems in experimental design. High variability among remnant fragments (e.g., different rates of selective logging in forests of eastern North America) can make interpreting statistical relationships of fragment attributes and plant communities quite complicated (Doak and Mills 1994), and the lack of historical (prefragmentation) data on plant distributions limits the conclusions based on the occurrence of a plant in present landscapes (Zimmerman and Bierregaard 1986). More importantly, none of these studies provide direct evidence that fragmentation leads to higher probabilities of population extinctions. This is surprising given that the prediction of population changes in fragmented habitats has become accepted as a "central tenet" of applied ecology.

Several studies suggest that edge effects and reduced fragment size can influence various life history stages of plants, although none of these have been associated with actual changes in population viability. These include studies of seed set (Sork 1983, Aizen and Feinsinger 1994), plant-pollinator interactions (Powell and Powell 1987, Jennersten 1988, Aizen and Feinsinger 1994; reviewed in Rathcke and Jules 1993), and herbivory (Andrén and Angelstam 1993, Santos and Telleria 1994). The main purpose of the work presented here was to determine if habitat fragmentation has resulted in demographic changes associated with increased extinction risk, and also to determine the proximal mechanisms underlying these changes. 
The study was conducted in a $250-\mathrm{km}^{2}$ watershed in the Siskiyou Mountains of southwestern Oregon in which clearcut logging practices have fragmented the forest over the past $35 \mathrm{yr}$. Robert Whittaker did a seminal plant community study in this watershed in 1949 (Whittaker 1960), providing useful estimates of prefragmentation densities of many vascular plants. I conducted my study using a perennial understory herb surveyed in his study, western trillium (Trillium ovatum Pursh., Liliaceae), which can be aged because it produces annual constrictions on underground rhizomes (Brandt 1916; see also Hanzawa and Kalisz 1993). This unusual trait, along with its nonclonal habit, makes trillium an ideal plant for demographic research. In addition, because individual trillium plants can live much longer than the 35-yr period of logging (at least $72 \mathrm{yr}$; see Results: Plantation surveys) the study area provides an excellent system in which demographic changes for populations in both clearcut sites and remnant fragments can be assessed.

Specifically, the goals of this study were (1) to describe the distribution of trillium after forest fragmentation in relation to Whittaker's pre-fragmentation survey, and (2) to test the hypothesis that if fragmentation reduces the area of suitable habitat and increases edge effects, then populations in smaller fragments and/or closer to edges are more likely to become extinct. The trait of annual rhizome constrictions allowed for novel measurements of recruitment of trillium individuals since the time of fragmentation. These data are useful for predicting population declines, which consequently lead to increased extinction risk associated with small population sizes (e.g., MacArthur and Wilson 1967, Lande 1988). The main component of my study used eight populations that varied in (1) the size of the fragment in which they were found, (2) their distance to the adjacent clearcut edge, and (3) the number of years the edge had been present. Among other things, recruitment, survivorship, seed set, and herbivory were measured in each population. A second component of my study specifically addressed edge effects, and included similar measures taken along five transects each of which extended from an edge into the forest interior within a single forest fragment.

\section{Materials and Methods}

\section{Study area and organism}

Western trillium (Trillium ovatum) is a common herbaceous plant found in mesic forested sites from Colorado to western Canada, south through the Cascades in Oregon and the California Coast Range as far as Monterey County (36³0' N latitude; Hickman 1993). Underground rhizomes usually produce one stem each year with either one or three leaves, although occasionally two stems are produced in older plants. Stem production creates an annual constriction on the rhizome, although age estimates for older plants are un- derestimates because most plants $>30 \mathrm{yr}$ of age have lost small portions of rhizome due to decay (Jules 1997). Trillium produces several different life history stages: a cotyledon stage, one-leaf vegetative stage, three-leaf vegetative stage, and three-leaf reproductive stage. Each reproductive trillium stem produces one flower in early spring that can produce $1-150$ seeds (Mesler and Lu 1983). Reproductive individuals are self-incompatible, and pollination is accomplished primarily by sap beetles, rove beetles, flower long-horned beetles, bumble bees, and honey bees (Levkowitz 1984, Jules 1997). Trillium seeds have attached food bodies (elaiosomes) that are attractive to both ants and yellow jacket wasps. While these insects do not destroy seeds, they act as dispersal agents by transporting seeds with elaiosomes away from fruits (Jules 1996).

The Siskiyou Mountains of southwestern Oregon are part of the Klamath Mountains province, a series of steeply cut mountain ranges on the California-Oregon border that interrupt both the Coast Range and the Sierra-Cascade Mountain complex (Ramp and Peterson 1979). The study was conducted in the Sucker Creek watershed, a drainage in the central Siskiyous that forms the eastern boundary of the Illinois Valley ( $\sim 50$ $\mathrm{km}$ inland from the Pacific coast). Almost the entire watershed is within the Siskiyou National Forest.

The Sucker Creek watershed generally drains in an east to west direction and ranges in elevation from 540 to $2100 \mathrm{~m}$. Lower-elevation forests in the watershed are dominated by Douglas-fir (Pseudotsuga menziesii) and hardwoods such as tanoak (Lithocarpus densiflorus) and Pacific madrone (Arbutus menziesii). Mid- to high-elevation forests, which are cooler and moister in summer, are dominated by Douglas-fir and white fir (Abies concolor) and have rich herbaceous communities. Common understory herbs include vanilla leaf (Achlys spp.), baneberry (Actaea rubra), woodland phlox (Phlox adsurgens), starflower (Trientalis latifolia), and western trillium.

Intensive clearcut logging of the forests described here began in the 1960s and has resulted in a mosaic of uncut forest surrounded by clearcuts and tree plantations. Approximately $40 \%$ of the late-successional forest in the Sucker Creek watershed has been harvested (U.S. Department of Agriculture 1995), and forest fragments range in size from 0.3 ha to $\sim 1000$ ha (Mills 1995). Besides isolating remnant forests, the most significant effect of logging has been to increase the ratio of forest edge to forest interior, which exposes understory vegetation to desiccating winds that blow through open edges, as well as to changes in solar radiation (Chen et al. 1995, Mills 1996). Sites from which timber has been harvested have experienced the following management regime: clearcut logging, broadcast burning (controlled burning of the entire site) to remove debris and vegetation, and planting of conifer seedlings (mostly Douglas-fir). As a result, the watershed contains a patchwork of many even-age plan- 
TABLE 1. Characteristics of eight clearcuts/plantations with demographic information for Trillium ovatum found in each.

\begin{tabular}{|c|c|c|c|c|c|c|c|c|c|c|c|}
\hline $\begin{array}{l}\text { Plan- } \\
\text { tation }\end{array}$ & $\begin{array}{c}\text { Elevation } \\
(\mathrm{m})\end{array}$ & $\begin{array}{c}\text { Aspect } \\
\left({ }^{\circ}\right)\end{array}$ & Year cut & Burned? & $\begin{array}{l}\text { Mean tree } \\
\text { height }(\mathrm{m})\end{array}$ & $\begin{array}{l}\text { Total } \\
\text { plants } \\
\text { found }\end{array}$ & $\begin{array}{c}\text { Plant } \\
\text { density } \\
\left(\text { no. } / \mathrm{m}^{2}\right)\end{array}$ & $\begin{array}{l}\text { No. } \\
\text { repro- } \\
\text { ductive }\end{array}$ & $\begin{array}{l}\text { Seed density } \\
\quad\left(\text { no. } / \mathrm{m}^{2}\right)\end{array}$ & $\begin{array}{c}\text { No. } \\
\text { younger }\end{array}$ & $\begin{array}{c}\text { Recruitment } \\
\text { estimate }\end{array}$ \\
\hline 1 & 1247 & 260 & 1980 & $\mathrm{~N}$ & 6.5 & 36 & 0.0054 & 19 & 0.0053 & 5 & 0.00075 \\
\hline 2 & 1444 & 260 & 1980 & $\mathrm{Y}$ & 5.5 & 10 & 0.0031 & 4 & 0.0032 & 0 & 0 \\
\hline 3 & 1575 & 230 & 1965 & $\mathrm{Y}$ & 14 & 6 & 0.0012 & 2 & 0.0011 & 0 & 0 \\
\hline 4 & 1588 & 225 & 1979 & Y & 2 & 0 & 0 & 0 & 0 & 0 & 0 \\
\hline 5 & 1509 & 275 & 1959 & $\mathrm{Y}$ & $1 \overline{5}$ & 32 & 0.0062 & 4 & 0.0018 & 25 & 0.00483 \\
\hline 6 & 1575 & 255 & 1981 & $\mathrm{Y}$ & 2.5 & 13 & 0.0053 & 12 & 0.01222 & 0 & 0 \\
\hline 7 & 1627 & 285 & 1968 & $\mathrm{~N}$ & 8.5 & 10 & 0.0024 & 6 & 0.0031 & 0 & 0 \\
\hline 8 & 1411 & 255 & 1978 & $\mathrm{Y}$ & 9.5 & 0 & 0 & 0 & 0 & 0 & 0 \\
\hline
\end{tabular}

Notes: Burned clearcuts are those that were broadcast burned (controlled burning of the entire logged area) to remove woody debris and shrubs after logging. "Number younger" refers to plants found that were younger than the time since logging (i.e., recruited into the site since logging). Recruitment estimates are the densities of plants recruited into the clearcut/ plantation per year since logging.

tations in various stages of growth; trees in some of the oldest plantations now reach $20 \mathrm{~m}$ in height $(\mathrm{E}$. Jules, personal observation).

Whittaker (1960) conducted a major portion of a plant community study within the Sucker Creek watershed in 1949, just prior to the initiation of largescale logging. His work documented that trillium obtains its greatest abundance in forests between 1370 and $1680 \mathrm{~m}$ elevation in the Siskiyou Mountains. Other studies indicate that within this forest type trillium is least abundant on south-facing slopes and more abundant on west- and north-facing slopes (Frost 1992). Because west-facing slopes dominate the westwardflowing Sucker Creek watershed, my study was done on a range of west-facing sites within the elevation range at which Whittaker observed the greatest density of trillium.

\section{Plantation surveys}

Initial inspections of plantations in the Sucker Creek watershed suggested that few trillium individuals were present in these sites, and no distinct populations were available for demographic study. Thus, surveys of entire plantations were made to determine the effect of timber harvesting and conifer replanting on trillium. Eight west-facing plantations were chosen to represent a broad range of tree heights and stand ages. The plantations surveyed were 4 to 20.4 ha in size (mean = $11.3 \mathrm{ha}$ ), and $1250-1630 \mathrm{~m}$ in elevation (mean $=1500$ m; Table 1). In mid-July 1995 a series of transects, each $4 \mathrm{~m}$ wide, were surveyed across plantations following topographic contours. A sufficient number of transects was used to ensure that $10 \%$ of the total plantation was surveyed. Within the transects the age of all trillium plants was determined by excavating rhizomes. Preliminary work suggested that most individuals would survive this process if reburied immediately (E. Jules, unpublished data). Plant stage and seed production were also recorded.

The total density of trillium in each plantation was calculated and compared to the density of trillium derived from Whittaker (1960). In his study the average density of trillium (between 1370 and $1680 \mathrm{~m}$ and on a "reasonably even representation of topographic sites" [p. 286]) was 0.126 plants $/ \mathrm{m}^{2}$. Using my data, I also calculated a recruitment estimate, defined as the density of plants that had been recruited into the plantation per year since clearcutting. The year of clearcutting ranged from 1965 to 1980 (clearcutting dates from the U.S. Department of Agriculture Forest Service; Table 1).

\section{Forest fragment populations}

Habitat fragmentation is thought to decrease population viability due to the reduction and isolation of habitat and also the climatic and biological changes associated with habitat edges (Wilcove et al. 1986, Lande 1988, Yahner 1988, Saunders et al. 1991). To test whether fragmentation had changed recruitment and/or survivorship in populations within fragments, eight populations of trillium in separate fragments were surveyed. To minimize variation from outside sources, I chose discrete populations that were all in old-growth forests dominated by Douglas-fir and that had not experienced recent fires. All populations were on westfacing slopes of 1340-1640 m elevation (mean $=1500$ $\mathrm{m})$ that harbored similar herbaceous plant communities. Though I used only one population in a given fragment, fragments each contained $>1$ population. For each population I measured: (1) fragment size, (2) distance to the nearest clearcut edge ("nearest edge"), (3) the distance to the nearest edge that faced the prevailing winds (the west-facing, or "wind edge"), (4) the number of years these edges had been present, (5) aspect, and (6) elevation.

Using a spherical densiometer (Forest Densiometers, Arlington, Virginia, Model-A), I determined percent open canopy at three randomly selected points within each population (between 24 June and 11 July 1995). The mean of these three points was used as a measure of incident light for each population. Soil moisture was estimated by collecting a $200-\mathrm{cm}^{3}$ core sample from five randomly selected sites within each population and then determining water content as a percentage of dry 
TABLE 2. Fragmentation attributes and demographic information for eight populations of Trillium ovatum within separate forest fragments.

\begin{tabular}{|c|c|c|c|c|c|c|c|c|c|c|c|c|}
\hline \multicolumn{13}{|c|}{ Fragment attributes } \\
\hline \multirow[b]{2}{*}{$\begin{array}{l}\text { Popula- } \\
\text { tion }\end{array}$} & \multirow{2}{*}{$\begin{array}{l}\text { Fragment } \\
\text { size } \\
\text { (ha) }\end{array}$} & \multicolumn{2}{|c|}{ Nearest edge } & \multicolumn{2}{|c|}{ Wind edge } & \multirow[b]{2}{*}{$\begin{array}{c}\text { Aspect } \\
\left({ }^{\circ}\right)\end{array}$} & \multirow[b]{2}{*}{$\begin{array}{l}\text { Elevation } \\
\quad(\mathrm{m})\end{array}$} & \multirow[b]{2}{*}{$\begin{array}{l}\% \text { open } \\
\text { canopy }\end{array}$} & \multirow{2}{*}{$\begin{array}{c}\text { Soil } \\
\text { moisture } \\
\text { (\% dry } \\
\text { mass) }\end{array}$} & \multirow[b]{2}{*}{$\begin{array}{l}\text { Pop. } \\
\text { size }\end{array}$} & \multirow[b]{2}{*}{$\begin{array}{l}\text { Area } \\
\left(\mathrm{m}^{2}\right)\end{array}$} & \multirow{2}{*}{$\begin{array}{c}\text { Plant } \\
\text { density } \\
\left(\text { no. } / \mathrm{m}^{2}\right)\end{array}$} \\
\hline & & $\begin{array}{l}\text { Dist. } \\
\text { (m) }\end{array}$ & $\begin{array}{l}\text { Time } \\
(\mathrm{yr})\end{array}$ & $\begin{array}{l}\text { Dist. } \\
\text { (m) }\end{array}$ & $\begin{array}{c}\text { Time } \\
(\mathrm{yr})\end{array}$ & & & & & & & \\
\hline I & 2.97 & 67 & 16 & 126 & 30 & 261 & 1342 & 4.40 & 7.60 & 53 & 165 & 0.321 \\
\hline II & 3.72 & 65 & 14 & 67 & 14 & 260 & 1464 & 7.80 & 12.4 & 48 & 104 & 0.462 \\
\hline III & 6.48 & 61 & 29 & 85 & 9 & 225 & 1464 & 3.60 & 26.5 & 26 & 85 & 0.306 \\
\hline IV & 11.9 & 30 & 13 & 30 & 13 & 255 & 1586 & 4.10 & 21.0 & 64 & 264 & 0.242 \\
\hline V & 62.09 & 84 & 30 & 135 & 34 & 280 & 1556 & 3.60 & 14.7 & 116 & 180 & 0.644 \\
\hline VI & 116.74 & 97 & 26 & 130 & 25 & 285 & 1495 & 3.10 & 17.6 & 56 & 154 & 0.364 \\
\hline VII & 215.99 & 16 & 16 & 16 & 16 & 290 & 1647 & 10.6 & 18.4 & 58 & 90 & 0.644 \\
\hline VIII & $\sim 1000$ & 332 & 24 & 332 & 24 & 285 & 1495 & 15.6 & 21.0 & 129 & 156 & 0.827 \\
\hline
\end{tabular}

Demographics

\begin{tabular}{|c|c|c|c|c|c|c|c|c|c|c|}
\hline \multirow[b]{2}{*}{$\begin{array}{l}\text { Popula- } \\
\text { tion }\end{array}$} & \multirow[b]{2}{*}{$\begin{array}{c}\text { Survivor- } \\
\text { ship } \\
(1994- \\
1995)\end{array}$} & \multirow[b]{2}{*}{$\begin{array}{c}\text { Her- } \\
\text { bivory } \\
\quad 1\end{array}$} & \multirow[b]{2}{*}{$\begin{array}{c}\text { Her- } \\
\text { bivory } \\
2\end{array}$} & \multicolumn{2}{|c|}{1993} & \multicolumn{2}{|c|}{1994} & \multirow[b]{2}{*}{$\begin{array}{l}\% \text { inds. } \\
\text { juvenile } \\
\text { age }\end{array}$} & \multirow[b]{2}{*}{ R.E.N. } & \multirow[b]{2}{*}{ R.E.W. } \\
\hline & & & & $\begin{array}{c}\text { Seed } \\
\text { density } \\
\left(\text { no. } / \mathrm{m}^{2}\right)\end{array}$ & $\begin{array}{l}\text { Seeds per } \\
\text { repro. plant }\end{array}$ & $\begin{array}{c}\text { Seed } \\
\text { density } \\
\left(\text { no. } / \mathrm{m}^{2}\right)\end{array}$ & $\begin{array}{l}\text { Seeds per } \\
\text { repro. } \\
\text { plant }\end{array}$ & & & \\
\hline I & 0.444 & 0.50 & 0.45 & 1.360 & 10.710 & 0.589 & 4.364 & 20.8 & 0.0053 & 0.0061 \\
\hline II & 0.550 & 0.13 & 0.10 & 0.040 & 0.290 & 1.865 & 8.083 & 6.3 & 0.0021 & 0.0021 \\
\hline III & 0.550 & 0.33 & 0.35 & 0.290 & 2.750 & 0.579 & 5.467 & 11.5 & 0.0069 & 0.0026 \\
\hline IV & 0.698 & 0.06 & 0.16 & 0.210 & 4.000 & 0.130 & 1.900 & 3.1 & 0.0006 & 0.0006 \\
\hline V & 0.380 & 0.38 & 0.36 & 0.940 & 10.000 & 0.191 & 2.646 & 22.4 & 0.0124 & 0.0132 \\
\hline VI & 0.542 & 0.13 & 0.14 & 0.300 & 2.000 & 0.027 & 0.263 & 3.6 & 0.0045 & 0.0044 \\
\hline VII & 0.452 & 0.12 & 0.41 & $\ldots$ & $\ldots$ & 1.350 & 7.147 & 6.9 & 0.0028 & 0.0028 \\
\hline VIII & 0.587 & 0.08 & 0.17 & 0.650 & 6.000 & 0.944 & 5.888 & 18.6 & 0.0182 & 0.0182 \\
\hline
\end{tabular}

Notes: The distance of the population from the nearest edge and the edge facing the prevailing wind (wind edge) are listed, as well as the time (in years) the edge has been present. Survivorship refers to the proportion of all plants in each population that survived from 1994 to 1995 . Herbivory was measured as the proportion of reproductive plants eaten by deer (see Methods: Forest fragment populations for differences between Herbivory 1 and 2). Percent juvenile age is the percentage of each population consisting of individuals $<15 \mathrm{yr}$ of age. Recruitment estimates are the densities of plants produced in the population per year since the adjacent clearcut harvest. R.E.N. is the recruitment estimate for time since the nearest edge was cut, and R.E.W. is the recruitment estimate for the time since the west-facing edge (i.e., the wind edge) was cut.

mass. These two measures, along with the six listed above, are collectively referred to as "fragment attributes" throughout this paper (Table 2). So I would be able to test the effects of fragment size and edge distance independently, I attempted to choose populations such that these variables were not significantly correlated.

During mid-July 1994 I excavated the rhizomes and estimated the ages of all plants in the eight study populations. Preliminary studies suggested that full leaf expansion had just been attained at the time of this study and no senescence had occurred (E. Jules, unpublished data). The stage class of all plants was also recorded and the position of each plant was recorded using an overlaid grid. Some additional individuals were found when the populations were resurveyed in 1995, either because individuals did not produce stems in 1994 or because herbivory by deer had eliminated stems prior to my 1994 survey. Plants found in either 1994 or 1995 are included in analyses of population age structures. However, because individual plants can alternate between stages (e.g., from reproductive in 1994 to vegetative in 1995), only data from 1994 were used for stage class analyses.

To test whether fragmentation influenced recruitment of new individuals into populations, I used two measures. First, the proportion of each population consisting of juvenile individuals was calculated. No plants $<15 \mathrm{yr}$ of age have been found flowering (Jules 1997), thus they were considered juveniles (i.e., nonreproductive). Second, an estimate of recruitment designed to detect changes in populations as a result of clearcut edge formation was calculated. This estimate equals the density of plants recruited into, and surviving to, the date of survey, in the population per year since the date of the adjacent clearcutting. This estimate was made for the time since both the nearest edge clearcut (recruitment estimate, nearest edge $=$ R.E.N.) and the wind edge clearcut (R.E.W.). I used both R.E.N. and R.E.W. in demographic analyses because I suspected that prevailing winds would increase the effects of edges on populations.

I used Spearman rank correlations to detect significant relationships between recruitment estimates and fragment attributes. Spearman correlations, which are highly conservative nonparametric tests, were used throughout the forest fragment study due to the low number of samples and the high number of correlations tested. Furthermore, because of the small sample sizes, Bonferroni-type adjustments made obtaining signifi- 
cant probability values extremely difficult. Thus, I calculated unadjusted probabilities as well as the $\alpha$ required for statistical significance using a Bonferroni technique. Both of these values are presented in my results. All statistical analyses were performed using SYSTAT (Wilkinson 1990).

To test whether survivorship was influenced by fragmentation, I measured the presence or absence in spring 1995 of all plants found in the 1994 surveys. For this variable, absence was regarded as a sign of mortality, although it should be noted that it is unknown if trillium individuals are capable of temporary dormancy. In general, my measures of mortality were unusually high (30-62\% of individuals), and this is certainly a result of excavating the rhizomes. Because logistic regression of survivorship on individual age indicated that age was not a significant determinant of survivorship in any population $(P \geq 0.10$ in all cases), a single value of survivorship for each population was used for analyses (proportion surviving). The proportion surviving was compared with fragment attributes using Spearman tests.

To determine if seed production might limit recruitment of new plants, I calculated the proportion of each population comprised of reproductive individuals (1994 only). As well, I counted seeds in all fruits of reproductive plants in 1993 and 1994. Proportion in reproductive stage, density of seeds produced in each population (seeds per square meter), and the mean number of seeds produced per reproductive plant were tested for significant correlations with fragment attributes and recruitment estimates using Spearman tests.

To assess if herbivory was related to fragmentation attributes, the proportion of reproductive plants that were eaten in each population during the summer of 1994 was measured. Only reproductive plants were used for the herbivory study, both because I could not measure herbivory on the large number of other plants and because my casual observations suggested that deer eat primarily reproductive trillium. Deer eat both the flower and leaves of trillium, leaving an unproductive stem that will not resprout until the following year. All reproductive plants were marked with a small piece of flagging around the base of the stem in early spring, and these plants were surveyed weekly for herbivory throughout the 1994 growing season. I refer to the proportion of these plants eaten as "Herbivory 1." In case plants that were not found in the 1994 demography survey but were found the following year had been eaten by deer, a second measure of herbivory was calculated. This measure ("Herbivory 2") is the proportion of the total population that was either eaten in 1994 or found only in 1995. Here I am making the untested assumption that absence in my 1994 survey indicates herbivory, in which case Herbivory 1 and 2 are estimates of the minimum and maximum herbivory levels, respectively. Herbivory 1 and Herbivory 2 were tested for correlations with fragment attributes and recruitment estimates using Spearman tests.

\section{Edge effect study}

To test specifically the influence of edge effects on recruitment of trillium individuals, one fragment was selected for a more detailed study (the fragment containing population II; Table 2). Randomly selected points along a 50-m stretch of the wind edge were used as the origin for five transects each of which stretched $70 \mathrm{~m}$ into the forest. Sampling was conducted within 10 - $\mathrm{m}$ intervals along the transects $(0-10,20-30,40-$ 50 , and 60-70 $\mathrm{m}$ from the edge). Age, stage, and seed production were recorded in July 1994 for each plant within $1 \mathrm{~m}$ to either side of the transect within the intervals $(10 \times 2 \mathrm{~m}$ plots $)$. A recruitment estimate was calculated for each interval within each transect. Since the wind edge of this fragment is also the nearest edge, and the edge had been produced $14 \mathrm{yr}$ ago, R.E.N., R.E.W., and proportion juvenile plants are equivalent and thus only one recruitment estimate was calculated (i.e., the density of plants recruited per year since the adjacent clearcutting). The relationship of distance (i.e., interval) from the edge and recruitment was compared by regressing recruitment on distance. In addition, seed production (seeds per square meter) in each interval was regressed on interval. Because only one of five transects had any trillium plants within the first interval $(0-10 \mathrm{~m})$, statistical analyses on proportions of plants in each stage class were not conducted; however, results are shown graphically. To ascertain the effects of forest edge on abiotic factors that may influence recruitment, percentage open canopy and percentage soil moisture were measured at one location in the center of each transect interval, and these measures also were regressed on distance.

\section{RESULTS}

\section{Plantation surveys}

No trillium individuals were found in two tree plantations, and very few were found in the other six (Table 1). In general, young plants have not been recruited into plantations since the date of clearcutting. Individuals found in plantations were as old as $72 \mathrm{yr}$. However, in six of the eight plantations no individuals younger than the age of the clearcutting date were found; for these six plantations the recruitment estimates were 0.0 plants $\cdot \mathrm{m}^{-2} \cdot \mathrm{yr}^{-1}$, and for two other plantations the estimates were 0.0008 and 0.0048 plants $\cdot \mathrm{m}^{-2} \cdot \mathrm{yr}^{-1}$ (Table 1). Similarly, of the 107 plants found, few plants were in young stage classes: one was a cotyledon $(0.9 \%$ of total), 9 were one-leaf vegetatives $(8.4 \%), 50$ were three-leaf vegetatives $(46.7 \%)$, and 47 were reproductives $(43.9 \%)$. Stand height in plantations, aspect, the use of broadcast burning after logging (for site preparation for conifer planting), and elevation did not explain differences in plant densities or recruitment of young plants (Table 1). 
TABLE 3. Correlation coefficients (Spearman's $r_{\mathrm{S}}$ ) between forest-fragment attributes among eight populations of Trillium ovatum.

\begin{tabular}{|c|c|c|c|c|c|c|c|}
\hline Fragment attribute & Aspect & Elev. & Frag. size & $\begin{array}{l}\% \text { open } \\
\text { canopy }\end{array}$ & Nearest edge & $\begin{array}{c}\text { Soil } \\
\text { moisture }\end{array}$ & Wind edge \\
\hline Aspect & $\cdots$ & & & & & & \\
\hline Elevation & 0.448 & $\ldots$ & & & & & \\
\hline Fragment size & $0.746 *$ & 0.687 & $\ldots$ & & & & \\
\hline \% open canopy & 0.325 & 0.091 & 0.240 & $\ldots$ & & & \\
\hline Nearest edge & 0.299 & -0.337 & 0.262 & -0.108 & $\ldots$ & & \\
\hline Soil moisture (\% dry mass) & -0.187 & 0.358 & 0.455 & -0.012 & -0.216 & $\ldots$ & \\
\hline Wind edge & 0.216 & -0.301 & 0.262 & -0.156 & $0.952 * * *$ & -0.096 & $\ldots$ \\
\hline
\end{tabular}

Notes: $N=8$ populations for all tests. $P$ values are unadjusted for the number of correlations tested; if a Bonferroni adjustment were used, significance would be indicated by $P \leq 0.002$ (i.e., $0.05 / 21$ ).

The average estimate of trillium density in plantations was 0.003 plants $/ \mathrm{m}^{2}$ (range $=0.0-0.0062$ plants/ $\mathrm{m}^{2}$; Table 1). Using Whittaker's data (1960), I estimate that on average only $2.4 \%$ of trillium individuals survived clearcutting and conifer replanting in these sites (0.003/0.126 of Trillium plants). It should be noted that Whittaker's data probably represent an underestimate of the density of trillium plants, because it is unlikely he recognized or counted cotyledons or one-leaf plants. Reduced recruitment cannot be attributed to a lack of seeds; reproductive plants in plantations produced an average of 24 seeds (range $=0-93$ seeds/plant), or an average of 0.003 seeds $/ \mathrm{m}^{2}$ (range $=0.0-0.012$ seeds $/$ $\mathrm{m}^{2}$; Table 1).

\section{Forest fragment populations}

Fragment attributes were not significantly correlated with each other, except that larger fragments tended to be on more north-facing slopes, and distances to the wind edge and the nearest edge were highly positively correlated (Table 3). The latter relationship was a result of the nearest edge and wind edge being the same edge for three of eight populations (Table 2). Because most attributes were statistically independent of one another, I eliminated those variables that were not related to fragmentation per se (i.e., aspect and elevation) from further analyses of demographic data. However, if fragment size was significantly correlated with a demographic parameter, then aspect would be included in an analysis with that parameter as well. In the comparison of fragment attributes, 21 correlations were performed, thus significance would be indicated by $P \leq 0.002$ (i.e., $0.05 / 21$ ) using a Bonferroni adjustment.

A total of 550 trillium plants were surveyed in the remnant forest populations, and the age of these plants ranged from 2 to $71 \mathrm{yr}$ (Fig. 1). While survivorship of plants from 1994 to 1995 was not significantly influenced by fragmentation attributes (Table 4), recruitment of new individuals was strongly correlated with edge distances. Populations closer to wind edges had recruited fewer new individuals per unit area since the date of edge formation than populations farther into the interior of forests (Table 4; Figs. 1 and 2). For example, the two populations closest to wind edges had
R.E.W. values of 0.0006 and 0.0028 plants $\cdot \mathrm{m}^{-2} \cdot \mathrm{yr}^{-1}$ (populations VII and IV, respectively), while the two populations farthest from the wind edge had R.E.W. values of 0.0132 and 0.0182 plants $\cdot \mathrm{m}^{-2} \cdot \mathrm{yr}^{-1}$ (populations $\mathrm{V}$ and VIII). The latter two R.E.W. values are both $>350 \%$ greater than either of the former two values. Populations closer to nearest edges also had lower recruitment estimates (R.E.N.), though the relationship was not quite as strong as for the wind edge distance and R.E.W. (Tables 2 and 3; Fig. 2). If a Bonferroni adjustment were applied to the correlations between recruitment, survivorship, and fragment attributes (i.e., Table 4), significant correlations would be indicated by $P \leq 0.003$.

Reduced recruitment was not correlated with a lack of reproductive plants; the proportion of each population consisting of reproductive plants was not related to fragment attributes (Table 5). Spearman tests showed positive correlations between seed production per unit area and recruitment estimates in 1993, though these were significant only for seed production and R.E.W. (Table 5). Correlation coefficients for seed production and recruitment estimates were very low in 1994 (Table $5)$. Herbivory 2 was strongly positively correlated with percent juvenile individuals (Table 5). If a Bonferroni technique were applied to the correlations in this set of tests (i.e., Table 5), significance would be indicated by $P \leq 0.001$.

\section{Edge effect study}

A total of 129 plants were surveyed within the five transects, and the age of these plants ranged from 2 to 53 yr. Recruitment estimates ranged from 0.0-0.05 plants $\cdot \mathrm{m}^{-2} \cdot \mathrm{yr}^{-1}$ in the interval plots. Recruitment estimates were lower in the two intervals closest to the edge than in the other intervals, though the relationship of recruitment with interval was not statistically significant (Fig. 3D; $F=2.87$, df $=1,18, P=0.108$ ). The relative proportion of plants in each stage class was generally consistent between intervals, except in the interval closest to the edge in which 8 of 10 plants were reproductive (Fig. $3 \mathrm{C}$ ). Seed production did not vary significantly across the distance to the edge ( $F=$ 0.289 , df $=1,18, P=0.159)$. 

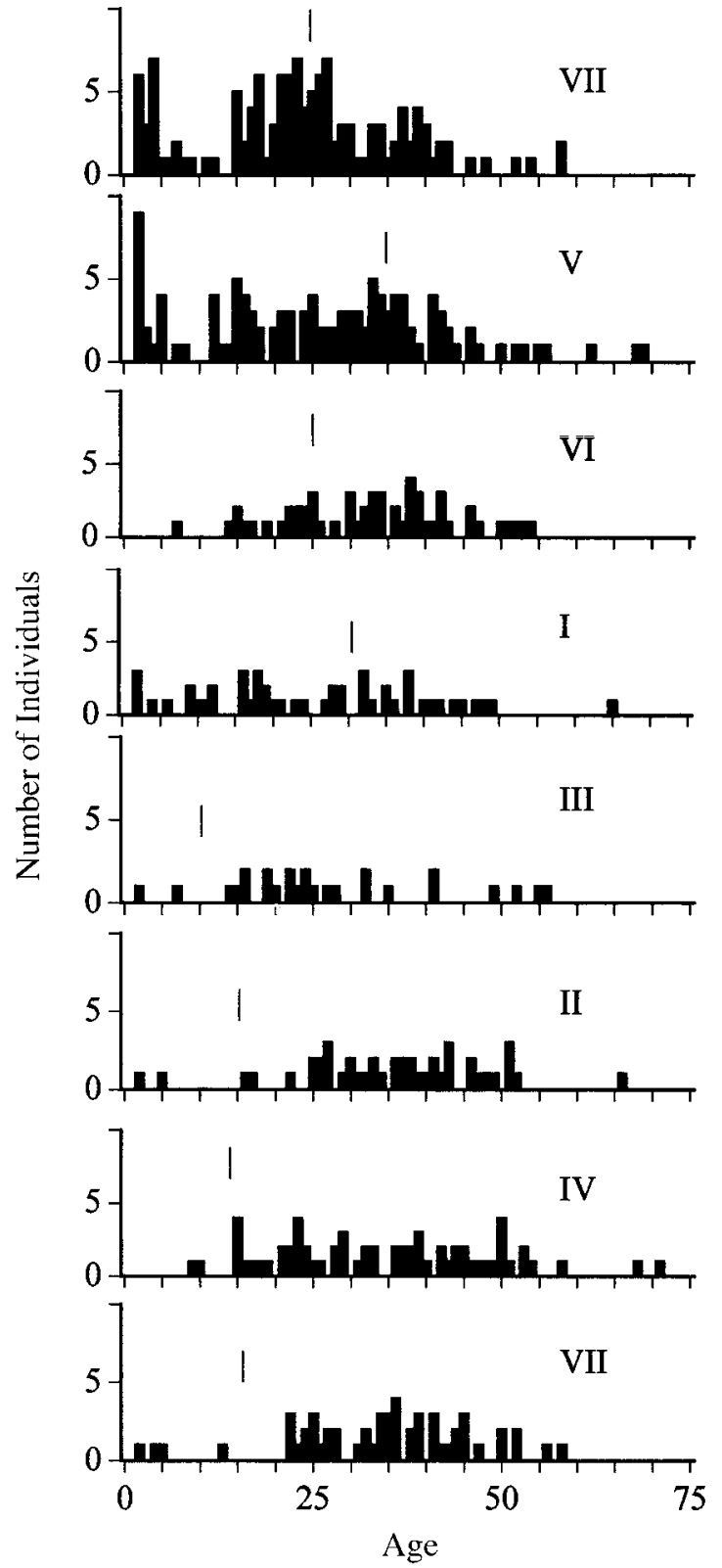

FIG. 1. Age class data for the eight populations of Trillium ovatum used in the forest fragmentation study. Roman numerals refer to populations listed in Table 2. Plants to the left of the short vertical lines are younger than the adjacent wind edge (clearcut to the west), and these plants are used to calculate the R.E.W. recruitment estimate. Populations are ordered from greatest to smallest wind edge distance (top to bottom).

Abiotic factors changed across intervals. The mean percent soil moisture was lower in interval-plots closer to the edge of the study-fragment than in plots farther into the forest interior, however this relationship was not statistically significant (Fig. $3 \mathrm{~A} ; F=1.5$, df $=1$, $18, P=0.238$ ). Interval-plots closer to the edge had significantly more open canopy than those in the interior (Fig. 3B, $F=9.2$, df $=1,18, P=0.001$ ).

\section{DISCUSSION}

The process of logging and conifer replanting in the Sucker Creek watershed results in high mortality $(\sim 97.6 \%)$ and almost no recruitment of Trillium ovatum individuals in clearcut sites (Table 1). Thus, this species is now largely restricted to fragments of uncut forest. Furthermore, remaining forest fragment populations near clearcut edges have recruited almost no new individuals since the edge was formed (Figs. 1, 2, and 3). Quantifying extinction probabilities would require demographic data for multiple years (see, for example, Menges 1990), though in this case short-term data can give qualitative predictions useful for estimating rates of decline. For instance, if no individuals live $>70 \mathrm{yr}$, and if recruitment estimates (R.E.W. in this calculation) remained constant for $70 \mathrm{yr}$, the two study-populations that were closest to wind edges would decrease in size by $54 \%$ and $83 \%$ (i.e., percentage of current population represented by: R.E.W. $\times 70 \mathrm{yr} \times$ population area), while the two populations farthest into forest interiors would increase by $43 \%$ and $54 \%$ (Table 2). Three of the four populations within 65 $\mathrm{m}$ of the nearest edge would experience dramatic decreases; these three populations would contain $\leq 18$ individuals after $70 \mathrm{yr}$. All four populations within 85 $\mathrm{m}$ of a wind edge would contain $\leq 18$ individuals after 70 yr. These percent decreases are underestimates, because they lack any estimates of mortality, including effects of competition and disturbance, and they do not account for changes in recruitment that would result from decreases in the number of reproductive plants. Regardless of the lack of population projections using matrix models, the data show that habitat fragmentation will decrease trillium population sizes and thus increase the likelihood of population extinction.

The results of this work, on the other hand, have several limitations typical of other studies of habitat fragmentation. Most importantly, the small sample size and large number of tested correlations in my forest fragment populations study made the detection of statistically significant relationships very difficult. In general, finding large numbers of appropriate fragments for study has been one of the greatest limitations for testing the effects of habitat fragmentation. Sample sizes in published population-level work have been less than ideal: for example, 2 fragments vs. 1 continuous habitat (Jennersten 1988); 5 small fragments vs. 5 large fragment vs. 5 continuous forests (Aizen and Feinsinger 1994); 8 fragments vs. 2 "large forests" (Santos and Telleria 1994); and 6 fragments (Klein 1989). As was true in my study, the difficulty of finding larger sample sizes arises for researchers from the need to limit variation in fragment characteristics that would reduce the power of detecting effects of fragmentation per se, such as variation in forest-type, elevation, and 
TABLE 4. Correlation coefficients (Spearman's $r_{\mathrm{S}}$ ) between forest-fragment attributes and demographic parameters for eight populations of Trillium ovatum.

\begin{tabular}{lcccr}
\hline \hline Fragment attribute & Juvenile age & $\begin{array}{c}\text { Recruitment estimate } \\
\text { (nearest edge) }\end{array}$ & $\begin{array}{c}\text { Recruitment estimate } \\
\text { (wind edge) }\end{array}$ & $\begin{array}{r}\text { Survivorship } \\
(1994-1995)\end{array}$ \\
\hline Fragment size & -0.048 & 0.310 & 0.489 & 0.132 \\
\% open canopy & 0.132 & 0.012 & 0.144 & 0.247 \\
Soil moisture & -0.275 & 0.132 & -0.204 & 0.639 \\
Nearest edge & 0.381 & $\mathbf{0 . 6 6 7} \dagger$ & not tested & -0.108 \\
Wind edge & 0.571 & not tested & $\mathbf{0 . 8 3 3 * *}$ & -0.180 \\
\hline
\end{tabular}

Notes: Recruitment estimates are the densities of plants produced in the population per year since either the nearest clearcut harvest or the nearest west-facing (wind edge) clearcut. $N=8$ populations for all tests. $P$ values are unadjusted for the number of correlations tested; significance would be indicated by $P \leq 0.003$ (i.e., 0.05/18) if a Bonferroni adjustment were used.

** $P=0.010, \dagger P=0.071$.
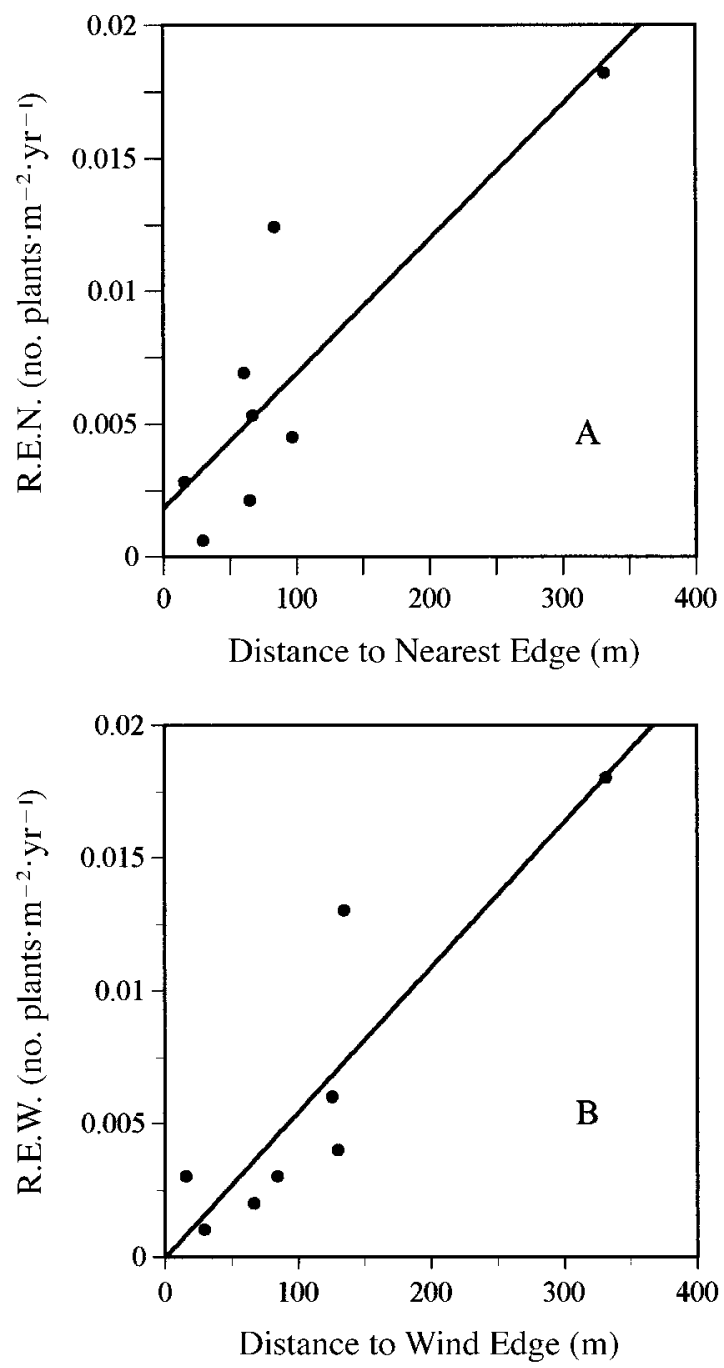

FIG. 2. The relationships between nearest edge and R.E.N. and between wind edge distance and R.E.W. for eight populations of Trillium ovatum used in the forest fragmentation study. R.E.N. is the recruitment estimate for the nearest edge, and R.E.W. is the recruitment estimate for the wind edge. Recruitment estimates are the densities of plants produced in the population per year since the adjacent clearcut harvest. Unadjusted Spearman rank tests produced: (A) $r_{\mathrm{s}}=$ $0.667, P=0.071$, and (B) $r_{\mathrm{s}}=0.833, P=0.010$. successional stage. However, while my sample size was modest and warrants cautious interpretation, the work is unique because it provides the first evidence of demographic changes resulting from habitat fragmentation for plants.

Unlike recruitment rates of younger plants, older age classes of trillium (three-leaf vegetative and reproductive plants) are not significantly influenced by edge effects (except at sites very close to clearcuts; e.g., Fig. $3 \mathrm{C})$. Stage class is generally a better predictor of seed production, growth, and survivorship for individual plants than is age class (Silvertown et al. 1993), and this is evidenced by similar rates of seed production per reproductive plant and similar survivorship rates for plants among my study populations. Apparently, plants that had established root systems when the adjacent clearcut was created have survived equally well regardless of distances from forest edge. And while seed production per unit area may be lower near edges in some years (Table 5), seed production is always greater than the number of new plants recruited per year. Because T. ovatum is self-incompatible (Levkowitz 1984), this suggests that effective pollination events and subsequent seed production, while possibly influenced by fragmentation, cannot solely be limiting recruitment.

Age and stage class data then, along with equivalent measures of herbivory across populations, suggest that mortality of extant plants and herbivory among populations can be eliminated as proximal causal mechanisms underlying the observed changes in recruitment. Several other mechanisms, however, may explain demographic changes associated with fragmentation of trillium habitat. Changes in seed dispersal, seed predation, germination rates, and survivorship of young plants may be altered near clearcut edges.

Changes in seed dispersal and predation may be responsible for reduced recruitment of trillium. Seeds of T. ovatum are dispersed by ants and occasionally by yellow jackets (Jules 1996), though seeds that fall passively from fruits can also become established (Mesler and Lu 1983). Both ants and yellow jackets are more abundant and active in warmer sites (i.e., forest edges; 
TABle 5. Correlation coefficients (Spearman's $r_{\mathrm{S}}$ ) of some population properties with edge distances and recruitment estimates, for eight populations of Trillium ovatum in the Siskiyou mountains of Oregon.

\begin{tabular}{|c|c|c|c|c|c|c|c|}
\hline \multirow[b]{2}{*}{ Attribute } & \multirow[b]{2}{*}{$\begin{array}{l}\text { Prop. } \\
\text { reproductive }\end{array}$} & \multirow[b]{2}{*}{ Herb. 1} & \multirow[b]{2}{*}{ Herb. 2} & \multicolumn{2}{|c|}{1993} & \multicolumn{2}{|c|}{1994} \\
\hline & & & & $\begin{array}{c}\text { Seeds } \\
\text { density } \\
\left(\text { no. } / \mathrm{m}^{2}\right)\end{array}$ & $\begin{array}{l}\text { Seeds per } \\
\text { repro. plant }\end{array}$ & $\begin{array}{c}\text { Seeds } \\
\text { density } \\
\left(\text { no. } / \mathrm{m}^{2}\right)\end{array}$ & $\begin{array}{l}\text { Seeds per } \\
\text { repro. plant }\end{array}$ \\
\hline $\begin{array}{l}\text { Nearest edge } \\
\text { Wind edge }\end{array}$ & $\begin{array}{l}-0.491 \\
-0.623\end{array}$ & $\begin{array}{l}0.204 \\
0.299\end{array}$ & $\begin{array}{r}-0.190 \\
0.000\end{array}$ & $\begin{array}{l}0.571 \\
0.714 \dagger\end{array}$ & $\begin{array}{r}0.214 \\
-0.381\end{array}$ & $\begin{array}{l}-0.214 \\
-0.262\end{array}$ & $\begin{array}{l}-0.405 \\
-0.381\end{array}$ \\
\hline R.E.N. & -0.539 & 0.343 & 0.311 & $0.714 \dagger$ & 0.512 & -0.024 & -0.048 \\
\hline R.E.W. & -0.503 & 0.361 & 0.407 & $0.821 *$ & 0.610 & -0.036 & -0.252 \\
\hline Percentage inds. juvenile age & -0.283 & 0.663 & $0.707 *$ & 0.655 & 0.108 & 0.132 & 0.108 \\
\hline
\end{tabular}

Note: $N=8$ populations for all tests except for 1993 seed data, where $N=7$ populations. $P$ values are unadjusted for the number of correlations tested; significance would be indicated by $P \leq 0.001$ (i.e., 0.05/35) if a Bonferroni adjustment were used.

$* P \leq 0.05, \dagger P=0.071$.
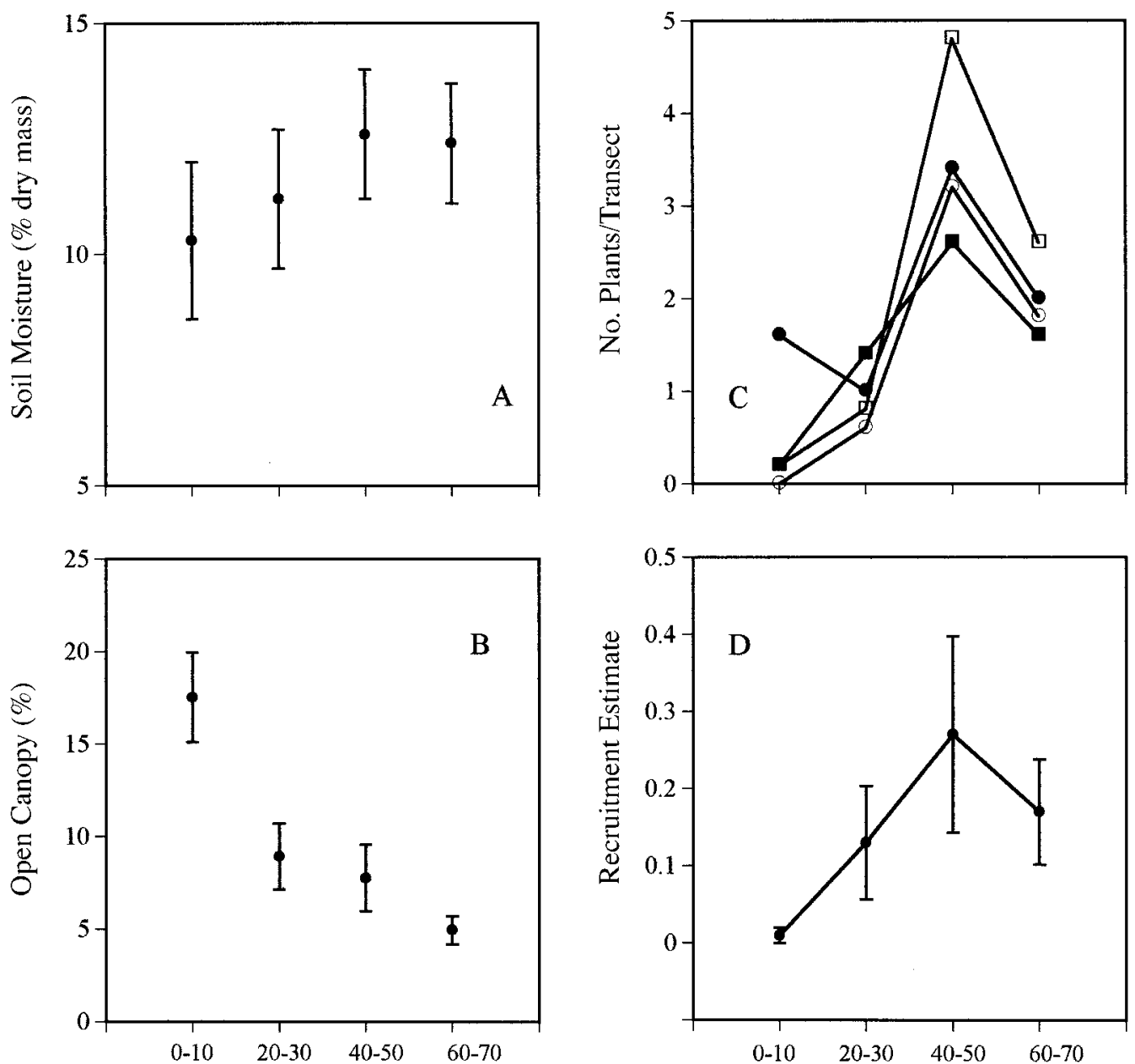

Transect Interval (m)

FIG. 3. The relationship of distance from edge into a forest along five transects that originate on a forest-clearcut edge $(0-10 \mathrm{~m})$ and end $70 \mathrm{~m}$ into the forest interior with (A) percent soil moisture, (B) percent open canopy, (C) mean number of each stage class of Trillium ovatum, and (D) mean recruitment estimate for $T$. ovatum. The recruitment estimate equals the density of plants produced per year since the adjacent clearcut harvest. For stage classes: $\square=\operatorname{cotyledons,~} \bigcirc=$ oneleaf vegetatives, $\square=$ three-leaf vegetatives, and $\mathbf{0}=$ reproductives. Each point is the mean of five transects (error bars show $\pm 1 \mathrm{SE})$. 
Mesler and Lu 1983, Jules 1996), and therefore a lack of recruitment in trillium populations is probably not due to an insufficient number of seed dispersers. On the other hand, trillium seeds are thought to be eaten by rodents, especially Peromyscus spp., and removal of trillium seeds from experimental platforms available only to rodents has been documented (Smith et al. 1989, Jules 1997). Mills (1993, 1995, 1996) found that 14 times as many deer mice (Peromyscus spp.) are present in clearcuts, and seven times as many are found along edges, than in forest interiors of southwestern Oregon. Although the actual level of seed predation (percent eaten) is unknown, changes in rodent communities near edges may explain reduced recruitment of trillium.

Abiotic changes associated with forest edges are well-documented and may reduce germination rates and establishment of trillium seedlings, a species typically found in mesic forested sites (Munz and Keck 1959). In general, most edges experience greater radiation flux (they are warmer in the day and cooler at night than interior habitats), greater water flux due to increased surface water flow and evaporation on clearings, and more wind, which contributes to an increase in both evapotranspiration and damage to vegetation near edges (Lovejoy et al. 1984, Saunders et al. 1991, Chen et al. 1993, Matlack 1993, Chen et al. 1995). Recruitment showed a significant relationship with both nearest edge and wind edge distances, but the relationship was strongest for wind edge distance (Fig. 2). This may suggest that the latter abiotic (wind-associated) changes are most important. However, while soil moisture and temperature are surely influenced by edges in my study region (Figs. 3A, B; Chen et al. 1995, Mills 1996), my measures of soil moisture and light were not correlated with recruitment of new plants in the eight remnant forest populations (Table 4).

Until recently, studies on plants in fragmented habitats have focused primarily on the relationship between species diversity and fragment size and isolation (Weaver and Kellerman 1981, Dzwonko and Loster 1989, Zacharias and Brandes 1990). In general, these studies indicate that larger fragments have greater diversity than smaller fragments. However, differences in diversity cannot always be attributed to fragmentation per se; this relationship is often a result of greater environmental heterogeneity in larger fragments, and that the influence of successional stage and site history can be more important than fragment size (Peterken and Game 1984, Gibson et al. 1988). Other problems limit the utility of these studies as well: sample sizes are often small (e.g., Weaver and Kellerman 1981), inappropriate controls are used by necessity (e.g., Middleton and Merriam 1983), and juvenile trees are usually considered an indication of future canopy composition, an inference that does not allow for differential mortality rates among species (e.g., Ranney et al. 1981). Moreover, none of these studies provide direct evidence supporting the principal prediction that has emerged from theoretical work on habitat fragmentation-that populations are more likely to become extinct in fragmented habitats.

In this study, fragment size was not related to estimates of recruitment for trillium (Table 4). However, smaller fragments consist of a greater proportion of edge habitat that is unsuitable for trillium than larger fragments. Accurately determining the distance into forests that is unsuitable for trillium is not yet possible and would require better projections for populations using measures of mortality and survivorship over multiple years. Still, there is a marked reduction in recruitment at sites near edges (Table 2). If, for example, habitat within $60 \mathrm{~m}$ of edges is unsuitable for trillium, a square-shaped 5-ha fragment would provide only a 1-ha area of suitable forest. Fragments are usually not square-shaped, thus a greater proportion of most fragments would be unsuitable. It is important to note, though, that edge effects are not uniform across aspects (Matlack 1993, Chen et al. 1995, Murcia 1995), as indicated by differences seen here between nearest edge and wind edge measures. The effects of edges are probably more severe on south and west-facing edges and less severe on north and east-facing edges (Chen et al. 1992, Frost 1992).

Results from this work are important in forested regions that have a dry summer climate that tends to strongly influence edge microclimate. Studies of plant communities in the Oregon Coast Range and on the western slope of the Cascade Mountains-areas that receive much greater precipitation in summer than the Siskiyous (Franklin and Dyrness 1973)_indicate that most trillium individuals can survive clearcut episodes in these regions (Halpern 1989, Halpern and Spies 1995; C. B. Halpern, personal communication). Differences in precipitation on recently logged sites may explain these contrasting observations. Trillium in the Sucker Creek watershed is bounded by drier habitat in which no trillium is found to the north (the Rogue Valley) and east (the inland rain shadow of the Siskiyous), and trillium habitat becomes progressively restricted to moist coastal forests of the California Coast Range to the south. In this sense, the Sucker Creek watershed is marginal habitat for trillium, and shifting the environment toward more xeric conditions will greatly influence organisms that are dependent on mesic forest.

At the landscape level, the fate of the few plants remaining in plantations is of great importance. In general, these plants are older than the clearcut areas, and even though they are producing seeds, they are unable to recruit new individuals into these sites. The rate at which plantations become suitable habitat for seed germination and survivorship of young plants (e.g., canopy closure) will determine whether the site is colonized by individuals within the site early in stand development or if seeds will need to be dispersed from trillium in other forests. Plants with ant-dispersed seeds 
colonize second-growth stands more slowly than plants with seeds dispersed by wind or by adhesion to or ingestion by animals (Matlack 1994), and this may limit the rate at which trillium can recolonize a plantation. On the other hand, dispersal by yellow jackets may aid in the movement of seeds into young forests since they forage much greater distances than ants, though how often yellow jackets disperse seeds has not been quantified yet (Jules 1996). Studies in eastern deciduous forests of North America show that three species of trillium ( $T$. grandiflorum, T. erectum, and T. luteum) have higher densities in primary forests than in secondary forest (Meier et al. 1995). The authors attribute this pattern to slow reproduction resulting from the clonal habit and ant-mediated seed dispersal mechanisms of these species.

In conclusion, the study presented here provides support for a key prediction about population responses to habitat fragmentation; the extinction of $T$. ovatum populations is more likely as a result declining population sizes near edges. Furthermore, this study suggests that the mechanism(s) of this demographic change is likely to be a combination of reduced seed set and survivorship of seeds and seedlings near edges. Unfortunately, predictions concerning the long-term effects of past management practices for other organisms in fragmented landscapes will be difficult to determine without substantially more field work. Yet, given that fragmentation can have severe consequences for even a common plant such as trillium, it is probable that the distribution and abundance of other understory plants have been significantly altered. For instance, numerous studies demonstrate that second-growth forests in $\mathrm{Eu}-$ rope and eastern North America have fewer herbaceous species compared with older forests (e.g., Dzwonko and Loster 1989, Duffy and Meier 1992; reviewed in Meier et al. 1995). In the Pacific Northwest, however, the long-term effect on species diversity of converting large amounts of forest to even-age plantations is poorly understood compared with these other forest-types (but see Halpern and Spies 1995). The likelihood of maintaining biological diversity in forests like those in the Sucker Creek watershed will increase by protecting areas that have never been harvested, minimizing the fragmentation of the landscape, and managing plantations in such a way that they can be colonized by organisms that favor mesic forests.

\section{ACKNOWLEDGMENTS}

This manuscript was greatly improved by comments from Beverly Rathcke, Deborah Goldberg, Terry Root, Lisa Curran, Thomas Miller, and two anonymous reviewers. I thank B. Rathcke and D. Goldberg for many useful discussions of this work. I also thank the following people for their assistance with fieldwork: Syndallas Baughman, Karen Beasely, Jennifer Beigel, Gail Borod, Adrienne Jules, Marcus Kauffman, Chris Meilinger, Shanie Mason, Amy Robohm, Bob Thacker, and Jude Urwin. Gary Fowler and George Estabrook gave much help with statistical analyses, and John Kasmer and Tim Howard helped with figures. Support for this work was provided by The American Philosophical Society, The Nature Conservancy, and the Department of Biology and Rackham Graduate School, University of Michigan.

\section{Literature Cited}

Aizen, M. A., and P. Feinsinger. 1994. Forest fragmentation, pollination, and plant reproduction in Chaco dry forest, Argentina. Ecology 75:330-351.

Andrén, H., and P. Angelstram. 1993. Moose browsing and Scots pine in relation to stand size and distance to forest edge. Journal of Applied Ecology 30:133-142.

Brandt, R. P. 1916. Notes on the California species of Trillium L. University of California Publications in Botany 7: 39-68.

Carelton, T. J., and S. J. Taylor. 1983. The structure and composition of a wooded urban ravine system. Canadian Journal of Botany 61:1392-1401.

Chen, J., J. F. Franklin, and T. A. Spies. 1992. Vegetation responses to edge environments in old-growth Douglas-fir forest. Ecological Applications 2:387-396.

Chen, J., J. F. Franklin, and T. A. Spies. 1993. Contrasting microclimates among clearcut, edge, and interior of oldgrowth Douglas-fir forest. Agricultural and Forest Meteorology 63:219-237.

Chen, J., J. F. Franklin, and T. A. Spies. 1995. Growingseason microclimatic gradients from clearcut edges into old-growth Douglas-fir forests. Ecological Applications 5: 74-86.

Doak, D. F., and L. S. Mills. 1994. A useful role for theory in conservation. Ecology 75:615-626.

Duffy, D. C., and A. J. Meier. 1992. Do Appalachian herbaceous understories ever recover from clearcutting? Conservation Biology 6:196-201.

Dzwonko, Z., and S. Loster. 1989. Distribution of vascular plant species in small woodlots on the western Carpathian foothills. Oikos 56:77-86.

Ewens, W. J. 1990. The minimum viable population size as a genetic and a demographic concept. Pages 307-316 in J. Adams, A. Hermalin, D. Lam, and P. Smouse, editors. Convergent issues in genetics and demography. Oxford University Press, New York, New York, USA.

Franklin, J. F., and C. T. Dyrness. 1973. Natural vegetation of Oregon and Washington. U.S. Department of Agriculture Forest Service, Portland, Oregon, USA.

Frost, E. J. 1992. The effects of forest-clearcut edges on the structure and composition of old-growth mixed conifer stands in the western Klamath Mountains. Thesis. Humboldt State University, Arcata, California, USA.

Gibson, D. J., S. L. Collins, and R. E. Good. 1988. Ecosystem fragmentation of oak-pine forest in the New Jersey Pinelands. Forest Ecology and Management 25:105-122.

Halpern, C. B. 1989. Early successional patterns of forest species: interactions of life history traits and disturbance. Ecology 70:704-720.

Halpern, C. B., and T. A. Spies. 1995. Plant diversity in natural and managed forests of the Pacific Northwest. Ecological Applications 5:913-934.

Hanzawa, F. M., and S. Kalisz. 1993. The relationship between age, size, and reproduction in Trillium grandiflorum. American Journal of Botany 80:405-410.

Harrison, S., and L. Fahrig. 1995. Landscape pattern and population conservation. Pages 293-308 in L. Hansson, L. Fahrig, and G. Merriam, editors. Mosaic landscapes and ecological processes. Chapman and Hall, London, UK.

Hickman, J. C. 1993. The Jepson manual: higher plants of California. University of California Press, Berkeley, USA. Jennersten, O. 1988. Pollination in Dianthus deltoides (Caryophyllaceae): effects of habitat fragmentation on visitation and seed set. Conservation Biology 2:359-366.

Jules, E. S. 1996. Yellow jackets (Vespula vulgaris) as a 
second seed disperser for the myrmecochorous plant, Trillium ovatum. American Midland Naturalist 135:367-369.

. 1997. History and biological consequences of forest fragmentation: a study of Trillium ovatum in southwestern Oregon. Dissertation. University of Michigan, Ann Arbor, Michigan, USA.

Klein, B. C. 1989. Effects of forest fragmentation on dung and carrion beetle communities in central Amazonia. Ecology 70:1715-1725.

Lande, R. 1988. Genetics and demography in biological conservation. Science 241:1455-1460.

Lawton, J. H. 1995. Population dynamic principles. Pages 147-163 in J. H. Lawton and R. May, editors. Extinction rates. Oxford University Press, New York, New York, USA.

Levkowitz, T. A. 1984. Pollination biology of Trillium ovatum Pursh. (Liliaceae) in Northern California. Thesis. Humbolt State University, Arcata, California, USA.

Lovejoy, T. E., J. M. Rankin, R. O. Bierregaard, Jr., K. S. Brown, Jr., L. H. Emmons, and M. E. Van der Voort. 1984. Ecosystem decay of Amazon forest remnants. Pages 295325 in M. H. Nitecki, editor. Extinctions. University of Chicago Press, Chicago, Illinois, USA.

MacArthur, R. H., and E. O. Wilson. 1967. The theory of island biogeography. Princeton University Press, Princeton, New Jersey, USA.

Margules, C. R., G. A. Milkovits, and G. T. Smith. 1994 Contrasting effects of habitat fragmentation on the scorpion Cercophonius squama and an amphipod. Ecology 75:20332042.

Matlack, G. R. 1993. Microenvironment variation within and among deciduous forest edge sites in the eastern United States. Biological Conservation 66:185-194.

- 1994. Plant species migration in a mixed-history forest landscape in eastern North America. Ecology 75: 1491-1502.

Meier, A. J., S. P. Bratton, and D. C. Duffy. 1995. Possible mechanisms for loss of vernal-herb diversity in logged eastern deciduous forests. Ecological Applications 5:935-946.

Menges, E. S. 1990. Population viability analysis for an endangered plant. Conservation Biology 4:52-62.

Mesler, M. R., and K. L. Lu. 1983. Seed dispersal of Trillium ovatum (Liliaceae) in second-growth redwood forest. American Journal of Botany 70:1460-1467.

Middleton, J., and G. Merriam. 1983. Distribution of woodland species in farmland woods. Journal of Applied Ecology 20:625-644.

Mills, L. S. 1993. Extinction in habitat remnants: proximate mechanisms and biogeographic consequences. Dissertation. University of California, Santa Cruz, California, USA. 1995. Edge effects and isolation: red-backed voles on forest remnants. Conservation Biology 9:395-403.

1996. Fragmentation of a natural area: dynamics of isolation for small mammals on forest remnants. Pages 199-219 in R. G. Wright, editor. Natural parks and protected areas. Blackwell, Cambridge, Massachusetts, USA.

Munz, P. A., and D. D. Keck. 1959. A California flora. University of California Press, Berkeley, California, USA

Murcia, C. 1995. Edge effects in fragmented forest: implications for conservation. Trends in Ecology and Evolution 10:58-62.

Peterken, G. F., and M. Game. 1984. Historical factors affecting the number and distribution of vascular plant species in the woodlands of central Lincolnshire. Journal of Ecology 72:155-182.

Powell, A. H., and G. V. N. Powell. 1987. Population dynamics of male Euglossine bees in Amazonian forest fragments. Biotropica 19:176-179.

Ramp, L., and N. V. Peterson. 1979. Geology and mineral resources of Josephine County, Oregon: State of Oregon
Department of Geology and Mineral Industries Bulletin 100.

Ranney, J. W., M. C. Bruner, and J. B. Levenson. 1981. The importance of edge in the structure and dynamics of forest stands. Pages 67-95 in R. L. Burgess and D. M. Sharpe, editors. Forest island dynamics in man-dominated landscapes. Springer Verlag, New York, New York, USA.

Rathcke, B. J., and E. S. Jules. 1993. Habitat fragmentation and plant-pollinator interactions. Current Science 65:273277.

Rolstad, J. 1991. Consequences of forest fragmentation for the dynamics of bird populations: conceptual issues and the evidence. Pages 149-163 in M. E. Gilpin and I. Hanski, editors. Metapopulation dynamics: empirical and theoretical investigations. Academic Press, London, UK.

Santos, T., and J. L. Telleria. 1994. Influence of forest fragmentation on seed consumption and dispersal of spanish juniper, Juniperus thurifera. Biological Conservation 70: 129-134.

Saunders, D. A., R. J. Hobbs, and C. R. Margules. 1991. Biological consequences of ecosystem fragmentation: a review. Conservation Biology 5:18-32.

Shaffer, M. L. 1981. Minimum population sizes for species conservation. Bioscience 31:131-134.

Silvertown, J., M. Franco, I. Pisanty, and A. Mendoza. 1993. Comparative plant demography-relative importance of life-cycle components to the finite rate of increase in woody and herbaceous perennials. Journal of Ecology 81:465476.

Simberloff, D. S. 1988. The contribution of population and community biology to conservation science. Annual Review of Ecology and Systematics 19:473-511.

Smith, B. H., P. D. Forman, and A. E. Boyd. 1989. Spatial patterns of seed dispersal and predation of two myrmecochorous forest herbs. Ecology 70:1649-1656.

Sork, V. L. 1983. Distribution of pignut hickory (Carya glabra) along a forest to edge transect, and factors affecting seedling recruitment. Bulletin of the Torrey Botanical Club 110:494-506

Soulé, M. E. 1987. Viable populations for conservation. Cambridge University Press, Cambridge, Massachusetts, USA.

U.S. Department of Agriculture Forest Service. 1995. Grayback/Sucker pilot watershed analysis, version 1.0. Siskiyou National Forest, Illinois Valley Ranger District, Cave Junction, Oregon, USA.

Verboom, J., A. Schotman, P. Opdam, and J. A. J. Metz. 1991. European nuthatch metapopulations in a fragmented agricultural landscape. Oikos 61:149-156.

Weaver, M., and M. Kellman. 1981. The effects of forest fragmentation on woodlot tree biotas in Southern Ontario. Journal of Biogeography 8:199-210.

Whittaker, R. H. 1960. Vegetation of the Siskiyou Mountains, Oregon and California. Ecological Monographs 30: 279-338.

Wilcove, D. S., C. H. McLellan, and A. P. Dobson. 1986. Habitat fragmentation in the temperate zone. Pages 237256 in M. E. Soulé, editor. Conservation biology: the science of scarcity and diversity. Sinauer Associates, Sunderland, Massachusetts, USA.

Wilkinson, L. 1990. SYSTAT: the system for statistics. SYSTAT, Evanston, Illinois, USA.

Yahner, R. H. 1988. Changes in wildlife communities near edges. Conservation Biology 2:333-339.

Zacharias, D., and D. Brandes. 1990. Species area-relationships and frequency-floristic data analysis of 44 isolated woods in northwestern Germany. Vegetatio 88:21-29.

Zimmerman, B. L., and R. O. Bierregaard. 1986. Relevance of the equilibrium theory of island biogeography and species-area relations to conservation with a case from Amazonia. Journal of Biogeography 13:133-143. 